\title{
«Консервативная революция» как феномен правого модерна в Веймарской республике
}

\begin{abstract}
Аннотачия. В статъе рассматривается проблема феномена идеологии «консервативной револючии» в интеллектуальном пространстве Веймарской республики в Германии. Автор дает общую характеристику «консервативной револючии» в контексте развития немеикого консерватизма в Веймарской республике и подчеркивает, что «консервативная революиия» была попыткой создания нового немецкого консерватизма и наиионализма радикального характера. “Консервативньх революиионеров» не устраивала система иенностей и политических кониепиий традичионного немечкого консерватизма, поэтому автор особо выделяет проблему соотношения традииионалистских и модернистских черт в идейном наследии «консервативных револючионеров". На примере идейно-политических кониепиий ведуших представителей «консервативной революиии»О. Шпенглера, А. Мёллер ван ден Брука, К. Шмитта, Э. Юнгера, Э. Никиша анализируются проблема их отношения к модерну и персональный вклад в формирование общего модернистского тренда интеллектуального феномена «консервативной револючии». Автор делает вывод о том, что «консервативные револючионеры» встали на путь поиска современных форм и методов репрезентачии своих взглядов, которые позичионировались ими как «новое мировоззрение» $и$ «новая идеология». Для этого они обратились к категориям модерна, итобы донести свои идеи до масс и выработать современные методы духовной борьбы со свочми идейнъми противниками. Идеология «консервативной революиии» стала одной из форм правого модерна.
\end{abstract}

Ключевые слова: «консервативная революиия», Веймарская республика, Германия, модернизм, традичионализм, наиионализм, правый модерн, О. Шпенглер, К. Шмитт, Э. Юнгер.

Review. This article examines the phenomenon of the ideology behind the "conservative revolution" within the intellectual space of the Weimar republic in Germany. The author gives a general description of the "conservative revolutionary movement" in the context of the development of German conservatism in the Weimar republic and notes that the "conservative revolutionary movement" was an attempt to create new German conservatism and nationalism of a radical nature. The "conservative revolutionaries" were not satisfied with the system of values and with the political concepts of traditional German conservatism, which is why the author addresses in detail the problem of the correlation between traditional and modernist traits in the ideological heritage of the "conservative revolutionaries". On the example of the ideological and political concepts of the leading representatives of the "conservative revolution" O. Spengler, A. Moeller van den Bruck, K. Schmitt, E. Jünger, E. Niekisch, the author analyses their views on modernism and their individual contribution to the formation of a general modernist trend in the intellectual phenomenon of the "conservative revolution". The author comes to the conclusion that the "conservative revolutionaries" took up a search for contemporary forms and methods of representing their views, which were positioned by them as a "new worldview" and a "new ideology". For this aim they used modernist categories to convey their ideas to the masses and to develop contemporary methods for theoretically combatting their ideological opponents. The ideology of the "conservative revolution" became one of the forms of right-wing modernism.

Key words: right-wing modernism, nationalism, traditionalism, modernism, Germany, Weimar republic, "conservative revolution”, O. Spengler, K. Schmitt, E. Jünger.

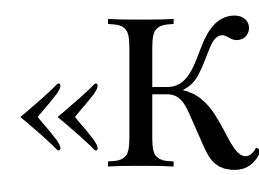

ого мы можем назвать консервативным в Веймарской республике?» - таким риторическим вопросом начинает свою монографию, посвященную эволюции германского консерватизма в Веймарской республике, современный немецкий историк Р. фон Буше $[13,1]$. Сам он констатирует, что до настоящего времени удовлетворительного ответа на этот вопрос в области исследований истории германского консерватизма так и не получено. Действительно, консерватизм в Веймарской ре- 
спублике представляет собой чрезвычайно пестрый конгломерат идеологических течений и политических партий и группировок от умеренно консервативных до праворадикальных.

Веймарская республика являлась средоточием глубоких и зачастую несовместимых друг с другом противоречий. В ней параллельно существовали и развивались глубокая архаика и самые передовые инновации в политике, культуре, экономике. Это придало дополнительный динамизм, но одновременно и трагизм ее существованию. По словам Г. А. Винклера, «14 лет первой германской республики были драматическим временем» $[1,11]$.

Специфика исторического развития Германии в период Веймарской республики соединилась с высшей точкой подъема общеевропейского кризиса классического модерна, или периода «рефлексивной модернизации», по терминологии известного германского социолога У. Бека [12], под которой он понимал ситуацию, когда модерн становится проблемой для самого себя и требует переосмысления своих базовых основ. Первые признаки этого процесса появились в конце XIX в., а Первая мировая война значительно его ускорила. Именно на 1920-1930-е гг. приходится пик духовного и общественно-политического кризиса в Европе, в рамках которого рождалась современная нам ситуация. «Рефлексивная модернизация» расширила интеллектуальные возможности познания окружающей действительности, что незамедлительно сказалось на трансформации основ базовых идеологий западного общества: консерватизма, либерализма и социализма.

Идеология немецкой «консервативной революции» - уникальное интеллектуальное явление в истории Германии XX в. Парадоксально было уже само словосочетание «консервативная революция», вобравшее в себя, казалось бы, несовместимые смысловые и лексические единицы. Феномен «консервативной революции» появился в Германии на пике общественно-политического кризиса 1918-1919 гг. Поражение кайзеровского рейха в Первой мировой войне, Ноябрьская революция, учреждение демократической Веймарской республики, Версальский мирный договор нарушили привычный жизненный уклад немецкого общества и перевернули общественные представления немцев. В условиях краха идеологии традиционного германского консерватизма среди молодого поколения немецких консерваторов возникает потребность обновления консервативной идеологии и политики, что привело к появлению феномена идеологии «консервативной революции».

«Консервативная революция» была попыткой создания нового немецкого консерватизма и национализма радикального характера. Четко очертить ее идейные и политические границы едва ли представляется возможным, т. к. она не обладала программным и политическим единством. Ее деятели стремились обновить германский консерватизм и придать ему современный и динамичный характер. Среди характерных черт «консервативной революции» можно выделить: национализм, антилиберализм, противопоставление немецкого народного духа и немецкой культуры ценностям западной цивилизации, поиск особого пути исторического развития Германии в русле «немецкого (прусского) социализма», идею корпоративного государства, бескомпромиссную борьбу против Веймарской республики. Эти черты делали «консервативную революцию» родственной национал-социализму - другому более радикальному течению германского консерватизма периода Веймарской республики в Германии.

«Консервативные революционеры» стремились к созданию национально-авторитарного государства корпоративного типа, но с развитым институтом частной собственности и высоким техническим оснащением экономики. Такое государство они предполагали достичь революционным, а не әволюционным путем. К числу видных протагонистов «консервативной революции» относят: Артура Мёллера ван ден Брука, Освальда Шпенглера, Эрнста Юнгера, Карла Шмитта, Эдгара Юлиуса Юнга, Ганса Церера, Эрнста Никиша и ряд других деятелей немецкого консерватизма в Веймарской республике.

Сущность идеологии «консервативной революции» заключалась в том, что, с одной стороны, «консервативные революционеры» выступали за сохранение национальной политической мифологии, с другой - понимали, что удержать ее в рамках традиционного германского консерватизма кайзеровской эпохи, ориентированного на классовые различия, невозможно. В этом отношении идеология «консервативной революции» сделала важный шаг вперед в эволюции германского консерватизма: ее ведущие теоретики отказались от классового понимания задач консерватизма и в своих идейных концепциях апеллировали к германской нации в целом.

«Консервативные революционеры» встали на путь поиска современных форм и методов ре- 


\section{Исторический журнал: научные исследования № 3 (27) • 2015}

DOI: $10.7256 / 2222-1972.2015 .3 .16545$

презентации своих взглядов, которые позиционировались ими как «новое мировоззрение»и «новая идеология». Они обратились к вербально-когнитивным категориям модерна, чтобы донести свои идеи до масс. Все это было сделано с изрядной долей политической наивности и романтизма, которые отражали факт их не совсем адекватного восприятия действительности. Образно говоря, «консервативная революция осталась в истории последним ярким явлением немецкого романтизма» [8, 13]. Тем не менее в трудах ведущих представителей «консервативной революции» была выражена характерная черта всего движения: попытка синтеза традиционализма и модернизма, что позволяет нам говорить об идеологии «консервативной революции» как о порождении эпохи модерна. По замечанию Р. П. Зиферле, «консервативная революция» и национал-социализм были направлениями, не альтернативными модерну, а проектами альтернативного модерна [17, 221], мы бы добавили: правого модерна.

Сами «консервативные революционеры» изначально ощущали свое отличие от традиционного немецкого консерватизма XIX - начала XX вв. Противоречие между традицией и модерном легло в основу интеллектуального и общественно-политического дискурса «консервативной революции». Характерный образец подобных умонастроений выразил еще в период становления идеологии «консервативной революции» О. Шпенглер. 27 декабря 1918 г. он писал своему близкому другу Г. Клёрису: «Поистине, наше будущее заключено, с одной стороны, в прусском консерватизме, после того как он полностью очистится от феодально-аграрной ограниченности, с другой стороны, в трудящихся, после того как они сами освободятся от анархо-радикальных масс» $[19,115]$.

В духовном и мировоззренческом отношении Шпенглер являлся последователем Ницше, заявившего, что «Бог умер». Он отрицал влияние церкви на процесс формирования государственной политики и скептически относился к идейному наследию прусского дворянства. В представлениях Шпенглера государство основывалось на принципе «воли к власти»и не нуждалось ни в какой божественной санкции. Политическое эссе «Пруссачество и социализм» произвело сильное впечатление на немецкую общественность, как и вышедший годом ранее первый том «Заката Европы». В книге, по мнению известного исследователя творчества
Шпенглера Д. Фелькена, была осуществлена поразительная интеллектуальная операция по освобождению прусского мифа от реакционного балласта и его примирению с социализмом. Социалистически обновленная прусская идея понималась не как потерпевшая крах, а как незавершенное призвание нации. «Пруссачество и социализм», как и все младоконсервативные сочинения того времени, преследовало двойную цель: прорыв к современности и разрушение демократии [15, 96].

Ведущий идеолог младоконсерватизма, одного из течений в пестрой идеологической палитре «консервативной революции», Артур Мёллер ван ден Брук в 1923 г. в книге «Третий рейх», своего рода «библии» немецкого «революционного консерватизма», попытался синтезировать национализм, социализм, революцию и имперскую идею. Он писал: «То, что сегодня является революционным, завтра станет консервативным. Мы хотим не продолжать революцию, а лишь подхватить идеи, которые остались еще непонятыми. Мы хотим увязать эти революционные идеи с консервативными, которые всплывают снова и снова. Мы хотим продвигать эту консервативную революцию, пока не добьемся условий, при которых мы сможем жить» $[3,132]$.

Далее он описывал немецкое государство, которое должно было явиться итогом «консервативной революции». Одновременно автор воскрешал германский идеал, берущий начало в апокалипсических пророчествах средневековых мистиков о «Третьем царстве». «Рейх», о котором грезил Мёллер ван ден Брук, должен был стать продолжением лучших традиций Священной Римской империи германской нации и Второй империи времен Бисмарка. В нем, по убеждению автора, воплотились бы мечты как революционеров-социалистов, так и националистов-консерваторов. Он выступил за синтез национальной и социалистической идей в форме «национального социализма». Вместе с тем достижение «Третьей империи» положило бы конец либерализму с его партиями и парламентской системой, понятием индивидуальной свободы и другими столь же ненавистными для «революционно консервативного» сознания атрибутами. Под «Третьим рейхом» Мёллер ван ден Брук понимал не просто историческое звено, которое следовало бы после Второго рейха Бисмарка и средневековой империи германских народов, а высшую цель исторического разви- 
тия немецкой нации и германского государства. Третий рейх Мёллера ван ден Брука - это конечный рейх, к которому всегда стремился немецкий национализм [18, 105].

В центре правовой и политической мысли К. Шмитта находилась категория «государство», которое он понимал в русле традиций немецкого обществознания как субстанциональное единство $[6,100]$. Из такого понимания государства вытекало отрицательное отношение К. Шмитта к либеральному государству. Немецкое государство не могло быть либеральным, ибо либерализм проповедует индивидуалистическо-персоналистический подход и не признает важность наличия какой-либо государственной идеи. Это противоречило духу немецкой политической традиции, основанной на консервативном понимании государства как целого [13, 196].

Интеллектуальные поиски К. Шмитта концентрировались на решении двух основных проблем. Во-первых, на борьбе с позитивистско-либеральной концепцией государства. Во-вторых, на разработке в условиях кризиса старой монархически-консервативной государственной идеи новых подходов к обоснованию немецкой сущности государства. «Субстанциональная однородность должна быть установлена - если потребуется - посредством отделения или уничтожения гетерогенного», - писал он по поводу концепции единого государства $[6,101]$.

Эти поиски новых, модернизированных подходов к обоснованию сущности немецкого государства в условиях галопирующего кризиса Веймарской республики привели Шмитта к обоснованию идеи диктатуры и тотального государства. «Суверенен тот, кто принимает решение о чрезвычайном положении», - провозглашает он $[9,15]$. Шмитт исходит из того, что все понятия современного учения о государстве представляют собой секуляризированные теологические понятия. Это означает, что современное правовое государство нарушает естественный ход вещей путем изгнания бога $[9,57]$, а вместе с ним и роли исключительного случая. Либеральному правовому конституционализму Шмитт противопоставляет учение о децизионизме (от лат. decisionis - решение), согласно которому в исключительной, не предусмотренной никакими юридическими нормами ситуации необходима воля применять неординарные решения. «Решение освобождается от любой нормативной связанности и становится в собственном смысле слова свободным» $[9,25]$.
Таким образом, Шмитт выступил как сторонник правовой концепции, основанной на чрезвычайных методах управления государством, а децизионизм он провозгласил в качестве антитезы нормативности в праве и политике. Категория «политического» используется Шмиттом не просто как синоним политики, но фактически подменяет собой категорию «государство». Важнейшим принципом политического являются воля и народное коллективное сознание, выражением которого должно стать государство, пронизывающее все сферы жизни. В условии абсолютного тождества политического и государства возникает феномен тотального государства [10, 292].

Шпенглер, Мёллер ван ден Брук, Шмитт находились в русле традиционалистского направления «революционного консерватизма», которое пыталось развивать свои идеи в контексте консервативно-охранительного дискурса. Представители этого направления, как мы показали выше, хотя и привнесли в идеологию «консервативной революции» модернистски ориентированные идеи, но развивали их в более традиционном идеологическом духе. Наиболее последовательный разрыв с традицией произошел в радикальном варианте «консервативной революции».

Характеризуя идеологические новации представителей радикального крыла «консервативной революции», следует признать, что в их центре стоит фигура Ә. Юнгера, интеллектуальное наследие которого является одним из ключевых феноменов «консервативной революции». А. В. Михайловский считает публицистику Юнгера «одним из наиболее ярких выражений “консервативно-революционной” политической мысли» [4, 334].

Юнгера по праву считают провозвестником нового понимания мира и человека. Он дал всеобъемлющую оценку последствиям наступления эпохи т. н. второго модерна с точки зрения ее философско-исторических, социально-философских и идейно-политических перспектив. Он стремился выявить как позитивное, так и негативное влияние модерна на общественное сознание. Анализ и критика различных политических проектов модерна стали характерной чертой творчества Юнгера как диагноста эпохи. Но он, вероятно, так и остался бы в ряду многочисленных критиков модерна, если бы не предпринял попытку сформулировать собственный идеологический и философский проект современного общества. 


\section{Исторический журнал: научные исследования № 3 (27) • 2015}

DOI: $10.7256 / 2222-1972.2015 .3 .16545$

Крах традиционных ценностей в ходе Первой мировой войны привел к революции нигилизма, которая разрушила существовавшие общественные и моральные устои. В Германии, стране, проигравшей войну, дух нигилизма проявился особенно остро. Юнгер с позиции «революционного консерватора» подверг критическому рассмотрению духовную и политическую ситуацию эпохи революции нигилизма. Юнгер искал интеллектуальный ключ к решению проблемы выведения Германии из состояния тяжелейшего морально-психологического шока, связанного с военным поражением. Его, как патриота и националиста, не устраивал ни либеральный, ни левый политический проект, ценности традиционного германского консерватизма также казались ему безнадежно устаревшими.

Юнгер выступал как один из видных основателей и апологетов идеологии «революционного (нового, солдатского) национализма», ставшего одним из главных идейных течений «консервативной революции». Характеризуя суть «революционного национализма», Юнгер писал: «Краеугольные камни в здании националистического государства - национализм в чистом виде, социализм, обороноспособность и авторитарная структура» $[11,103]$. Осуществлять этот проект должны были фигуры Солдата и Рабочего. Философское эссе «Рабочий» по праву считается одним из крупнейших произведений не только «консервативной революции», но и немецкой философской литературы XX в. Рабочий под пером Юнгера становится новым героем эпохи модерна, способным преодолеть ее противоречия. В образе рабочего перемешались социальные и политические архетипы эпохи Веймарской республики. Главной качественной характеристикой рабочего стало техническое мышление. «Техника - это тот способ, каким гештальт рабочего мобилизует мир», писал Юнгер [11, 235]. Образ рабочего носит у Юнгера внеклассовый, планетарный характер. Мифологема рабочего призвана объяснить неизбежность кризиса либерального государства и экономики и возникновение нового тотального общества.

По определению духовного лидера правого национал-большевизма в Веймарской Германии Э. Никиша, Юнгер «перевел духовное содержание русской революции и большевизма в немецкий способ мировосприятия и образ мышления» [5, 295]. Германский философ П. Козловский следующим образом характе- ризует идейную и мировоззренческую сущность «революционного национализма» Юнгера: «Модернизм Юнгера консервативен, а его консерватизм - модернистский. Его лозунг о тотальной мобилизации для Германии, его консервативный модернизм, является частью модерна, революция в Германии должна быть консервативной революцией» $[2,54]$.

В отличие от большинства ведущих идеологов «консервативной революции» Эрнст Никиш имел опыт участия в практической политике. В 1917 г. он вступил в ряды Социал-демократической рабочей партии Германии, в 1918-1919 гг. был председателем Центрального совета рабочих и солдатских депутатов в Мюнхене, активно участвовал в создании Баварской Советской республики. После ее краха вышел из СДПГ и вступил в Независимую социал-демократическую рабочую партию Германии, от которой с 1919 г. по 1922 г. был депутатом Баварского ландтага, а с 1922 г. - председателем объединенной фракции СДПГ и НСДПГ.

Но постепенно Никиш разочаровывается в левой идеологии. В 1923 г. он отказывается от мандата депутата Баварского ландтага, уезжает в Берлин, где быстро сближается с национал-большевиками из «Der Hofgeismarer Kreis», в состав которого входили молодые национально ориентированные социалисты, выступавшие против марксистского интернационализма и пропагандирующие идею национального социализма на основе сильного государства. С этого момента Никиш становится активным национал-болышевиком, а затем и духовным лидером правого национал-большевизма в Веймарской Германии, автором известной концепции «Сопротивления».

Суть этой концепции заключалась в следующем. Никиш писал: «Сопротивление было направлено против главной тенденции, которая явно возобладала в немецкой ответственной политике начиная с краха 1918 года: против готовности присоединиться к Западной Европе» $[5,235]$. По мнению Никиша, если перед Веймарской Германией стоял геополитический выбор, то он должен был однозначно решиться в пользу Востока, а не Запада, в пользу Советской России, а не Антанты.

Стратегия «Сопротивления» была призвана разрушить мосты, соединяющие Германию с буржуазным обществом. В этом сказывалась левая политическая основа взглядов Никиша, и в этом заключалась идейная основа немецкого правого национал-большевизма. Для Никиша 
большевистская Россия «была центром антиверсальского мира» $[5,236]$. Только вместо лозунга «пролетарской классовой борьбы» Никиш предлагал написать лозунг «национальной классовой борьбы». В национал-большевистской идеологии ортодоксально-марксистская идея о «пролетарской организации класса» уступает место идее о «пролетарской организации всего народа», что должно было привести к освобождению «всего народа», «национального целого».

В этой борьбе исключительную роль Никиш отводил прусскому наследию. «Пруссия как юнкерское государство всегда стояло в стороне от собственно Европы. Можно было теперь подчеркивать и культивировать эту антиевропейскую тенденцию Пруссии, ее враждебность Европе. Ее можно было свести не к юнкерству, а к системе нового порядка, а именно к националбольшевистской», - резюмировал Никиш [5, 241]. Согласно Никишу, «прусская идея службы постоянно находилась в противоречии с позицией буржуазного либерализма» $[5,241]$. Таким образом, национал-большевизм представлял собой перенос идеологии русского большевизма на прусскую национальную почву, которая должна быть освобождена от прусско-романтических традиций и заменена идеей пролетарской нации.

Характерна в связи с этим оценка Никишем концепции «прусского (немецкого) социализма», как известно, популярной во всех течениях «революционного консерватизма», разработанных представителями правого крыла «консервативной революции» Шпенглером и Мёллером ван ден Бруком. «Прусский социализм Шпенглера был тем засовом, который запирал немецкий дом, не давая войти в него настоящему социалисту, который не позволял дурить себе голову и выдавать капиталистический "X" за социалистический "Y” » [5, 220]. Мёллер ван ден Брук желал, по мнению Никиша, восстановить средневековую корпоративную систему, он «хотел снова запустить в обиход помещичью, юнкерскую патриархальность» $[5,220,221]$.

Говоря о значения Никиша для правонационалистического лагеря Веймарской республики, О. Ю. Пленков пишет: «Наряду с Освальдом Шпенглером Никиш дал наиболее впечатляю- щую и живую картину перспективы прусской традиции и сам последовательно воплощал ее в жизнь на протяжении всей долгой карьеры публициста и политика» $[7,8]$. К. О. Пэтель, как непосредственный деятель правого националбольшевизма в Веймарской республике, дает высокую, переходящую в пафос оценку Никишу. Национал-большевизм Никиша, его политическая концепция «Сопротивления» возникли, по мнению Пэтеля, на основе чувства национальной ответственности, которое демонстрировало молодое поколение социалистов и националистов в Веймарской республике и которое видело возможность интеграции пролетарских масс в нацию путем достижения «национального социализма» $[16,80]$.

Л. Дюпё в своем фундаментальном исследовании национал-большевизма в Веймарской Германии считает это течение наиболее радикальным, а соответственно - наиболее репрезентативным для «консервативной революции». Никиш и его единомышленники по журналу «Widerstand» достигли, по мнению Дюпё, выдающихся результатов в обосновании духовных основ ультраправого национал-большевизма [14, 234]. Дюпё определяет политическую позицию Никиша как пролетарский национализм, призванный переориентировать пролетариат на дело служения нации $[14,242]$. Никиш воспринимал большевизм как идейную и политическую концепцию, противоположную влиянию Запада. Он пытался соединить в национал-большевизме фёлькишистские и революционно-консервативные тенденции [14, 330].

Подводя итог, можно констатировать, что ведущим идеологам «консервативной революции» было присуще достаточно современное видение немецкой действительности 1920-х начала 1930-х гг. «Консервативную революцию» следует рассматривать как одну из форм идеологии эпохи «массового общества», которая в образе праворадикального модерна предлагала альтернативную буржуазно-либеральной и социал-реформистской модель будущего. Как показала история, для Германии 1920-х гг., и особенно 1933-1945 гг., этот образ стал реальной исторической альтернативой.

\section{Библиография:}

1. Винклер Г. А. Веймар 1918-1933: история первой немецкой демократии. М: РОССПЭН, 2013. 878 с.

2. Козловский П. Миф о модерне: Поэтическая философия Эрнста Юнгера. М.: Республика, 2002. 239 с.

3. Мёллер ван ден Брук А. Третья империя // А. Мёллер ван ден Брук, А. Васильченко. Миф о вечной империи и Третий рейх. М.: Вече, 2009. С. 112-364. 


\section{Исторический журнал: научные исследования № 3 (27) • 2015}

DOI: $10.7256 / 2222-1972.2015 .3 .16545$

4. Михайловский А. В. Политическая публицистика Эрнста Юнгера в интеллектуальной истории Веймарской Германии // Юнгер Э. Националистическая революция. Политические статьи 1923-1933. М.: Издательская группа «Скименъ», 2008. C. $317-362$.

5. Никиш Э. Жизнь, на которую я отважился. Встречи и события. СПб.: Владимир Даль, 2012. 560 с.

6. Пивоваров Ю. С. Карл Шмитт. Политико-антропологический очерк // Россия и современный мир. 2001. № 4. С. 89-119.

7. Пленков О. Ю. Эрнст Никиш: попытка синтеза большевизма и прусской этики // Никиш Э. Политические сочинения. СПб.: Владимир Даль, 2011. С. 5-34.

8. Сендеров В. Кризис современного консерватизма // Новый мир. 2007. № 1. С. 117-151.

9. Шмитт К. Политическая теология. Сборник. М.: КАНОН-пресс, 2000. 336 с.

10. Шмитт К. Понятие политического // Антология мировой политической мысли. Т. 2. Зарубежная политическая мысль. ХХ в. М.: Мысль, 1997. 832 с.

11. Юнгер Э. Националистическая революция. Политические статьи 1923-1933. М.: Издательская группа «Скименъ», 2008. $366 \mathrm{c.}$

12. Beck U. Die Erfindung des Politischen: zu einer Theorie reflexiver Modernisierung. Frankfurt am Main: Suhrkamp, 1993. $302 \mathrm{~S}$.

13. Bussche R. von dem. Konservatismus in der Weimarer Republik: die Politisierung des Unpolitischen. Heidelberg: Universitätsverlag C. Winter, 1998. 428 S.

14. Dupeux L. «Nationalbolschewismus» in Deutschland 1919-1933: kommunistische Strategie und konservative Dynamik. München: Beck, 1985. 492 S.

15. Felken D. Oswald Spengler: Konservativer Denker zwischen Kaiserreich und Diktatur. München: Beck, 1988. 304 S.

16. Paetel, K. O. Versuchung oder Chance? Zur Geschichte des deutschen Nationalbolschewismus. Göttingen; Berlin; Frankfurt; Zürich: Musterschmidt, 1965. 343 S.

17. Sieferle, R. P. Die Konservative Revolution: fünf biographische Skizzen (Paul Lensch, Oswald Spengler, Ernst Jünger, Hans Freyer). Frankfurt am Main: Fischer-Taschenbuch-Verlag, 1995. 250 S.

18. Schwierskott, H. J. Arthur Moeller van den Bruck und der revolutionäre Nationalismus in der Weimarer Republik. Göttingen: Musterschmidt-Verlag, 1962. $202 \mathrm{~S}$.

19. Spengler O. Briefe 1913-1936 / Hrsg. von A.M. Koktanek. München: Beck, 1963. 817 S.

\section{References (transliterated):}

1. Vinkler G. A. Veimar 1918-1933: istoriya pervoi nemetskoi demokratii. M: ROSSPEN, 2013. 878 s.

2. Kozlovskii P. Mif o moderne: Poeticheskaya filosofiya Ernsta Yungera. M.: Respublika, 2002. 239 s.

3. Meller van den Bruk A. Tret'ya imperiya // A. Meller van den Bruk, A. Vasil'chenko. Mif o vechnoi imperii i Tretii reikh. M.: Veche, 2009. S. 112-364.

4. Mikhailovskii A. V. Politicheskaya publitsistika Ernsta Yungera v intellektual'noi istorii Veimarskoi Germanii // Yunger E. Natsionalisticheskaya revolyutsiya. Politicheskie stat'i 1923-1933. M.: Izdatel'skaya gruppa «Skimen», 2008. S. 317-362.

5. Nikish E. Zhizn', na kotoruyu ya otvazhilsya. Vstrechi i sobytiya. SPb.: Vladimir Dal', 2012. 560 s.

6. Pivovarov Yu. S. Karl Shmitt. Politiko-antropologicheskii ocherk // Rossiya i sovremennyi mir. 2001. № 4. S. 89-119.

7. Plenkov O. Yu. Ernst Nikish: popytka sinteza bol'shevizma i prusskoi etiki // Nikish E. Politicheskie sochineniya. SPb.: Vladimir Dal', 2011. S. 5-34.

8. Senderov V. Krizis sovremennogo konservatizma // Novyi mir. 2007. № 1. S. 117-151.

9. Shmitt K. Politicheskaya teologiya. Sbornik. M.: KANON-press, 2000. $336 \mathrm{~s}$.

10. Shmitt K. Ponyatie politicheskogo // Antologiya mirovoi politicheskoi mysli. T. 2. Zarubezhnaya politicheskaya mysl'. XX v. M.: Mysl', 1997. $832 \mathrm{~s}$.

11. Yunger E. Natsionalisticheskaya revolyutsiya. Politicheskie stat'i 1923-1933. M.: Izdatel'skaya gruppa «Skimen», 2008. $366 \mathrm{~s}$.

12. Beck U. Die Erfindung des Politischen: zu einer Theorie reflexiver Modernisierung. Frankfurt am Main: Suhrkamp, 1993. 302 S.

13. Bussche R. von dem. Konservatismus in der Weimarer Republik: die Politisierung des Unpolitischen. Heidelberg: Universitätsverlag C. Winter, 1998. 428 S.

14. Dupeux L. «Nationalbolschewismus» in Deutschland 1919-1933: kommunistische Strategie und konservative Dynamik. München: Beck, 1985. 492 S.

15. Felken D. Oswald Spengler: Konservativer Denker zwischen Kaiserreich und Diktatur. München: Beck, 1988. $304 \mathrm{~S}$.

16. Paetel, K. O. Versuchung oder Chance? Zur Geschichte des deutschen Nationalbolschewismus. Göttingen; Berlin; Frankfurt; Zürich: Musterschmidt, 1965. 343 S.

17. Sieferle, R. P. Die Konservative Revolution: fünf biographische Skizzen (Paul Lensch, Oswald Spengler, Ernst Jünger, Hans Freyer). Frankfurt am Main: Fischer-Taschenbuch-Verlag, 1995. 250 S.

18. Schwierskott, H. J. Arthur Moeller van den Bruck und der revolutionäre Nationalismus in der Weimarer Republik. Göttingen: Musterschmidt-Verlag, 1962.202 S.

19. Spengler O. Briefe 1913-1936 / Hrsg. von A.M. Koktanek. München: Beck, 1963. 817 S. 